\title{
Modelling and Operating Characteristics of Air-Cored Resonant Induction Machines
}

DOI:

10.1109/ECCE.2018.8557355

\section{Document Version}

Accepted author manuscript

Link to publication record in Manchester Research Explorer

\section{Citation for published version (APA):}

lacchetti, M., Deodhar, R., Smith, A. C., \& Mishima, K. (2018). Modelling and Operating Characteristics of AirCored Resonant Induction Machines. In IEEE: 2018 IEEE Energy Conversion Congress and Exposition (ECCE) https://doi.org/10.1109/ECCE.2018.8557355

\section{Published in:}

IEEE

\section{Citing this paper}

Please note that where the full-text provided on Manchester Research Explorer is the Author Accepted Manuscript or Proof version this may differ from the final Published version. If citing, it is advised that you check and use the publisher's definitive version.

\section{General rights}

Copyright and moral rights for the publications made accessible in the Research Explorer are retained by the authors and/or other copyright owners and it is a condition of accessing publications that users recognise and abide by the legal requirements associated with these rights.

\section{Takedown policy}

If you believe that this document breaches copyright please refer to the University of Manchester's Takedown Procedures [http://man.ac.uk/04Y6Bo] or contact uml.scholarlycommunications@manchester.ac.uk providing relevant details, so we can investigate your claim.

\section{OPEN ACCESS}




\section{Modelling and Operating Characteristics of Air- Cored Resonant Induction Machines}

\author{
Matteo F. Iacchetti \\ School of Electrical and Electronic Engineering \\ The University of Manchester \\ Manchester, UK \\ matteo.iacchetti@manchester.ac.uk \\ Rajesh P. Deodhar \\ IMRA Europe SAS UK Research Centre \\ Sussex University \\ Brighton, UK \\ rd@imra-ukrc.com
}

\author{
Alexander C. Smith \\ School of Electrical and Electronic Engineering \\ The University of Manchester \\ Manchester, UK \\ Sandy.Smith@manchester.ac.uk \\ Keisuke Mishima \\ IMRA Europe SAS UK Research Centre \\ Sussex University \\ Brighton, UK \\ km@imra-ukrc.com
}

\begin{abstract}
The performance of a high-speed air-cored induction machine (IMs) using capacitors to provide resonant operation is analyzed in this paper. Resonance can be obtained using the stator and rotor capacitors appropriately tuned with the machine inductances, though alternative options may be considered instead of rotor capacitors. The aim is to develop a simple analytical model for air-cored resonant induction machines and to use this to obtain an understanding of the operating principles and the limitations and issues. The analysis is based on the classical IM equivalent circuit supplemented with stator and rotor capacitors and considers different control scenarios to derive key expressions for resonance conditions, capacitor values, peak torque and efficiency and related slip values. The aim of this paper is to provide a full understanding of air-cored resonant IMs to assess the practicality of these machines.
\end{abstract}

Keywords-Induction Machines, Air Core, Resonance

\section{NOMENCLATURE}

$C_{s}, C_{r} \quad$ Stator, rotor capacitor.

$g \quad$ Mechanical airgap.

$h_{s}, h_{r} \quad$ Stator, rotor winding depth

$k_{\text {fill }} \quad$ Winding fill factor.

$k_{d k}, k_{p k}, k_{w k}$ Distribution, pitch, winding factor (harmonic $k$ )

$\bar{I}_{s}, \bar{I}_{r}^{\prime} \quad$ Stator, rotor (referred) current phasor.

$\ell \quad$ Machine axial length

$L_{s}, L_{m}, L_{r} \quad$ Stator, mutual, rotor inductance.

$m \quad$ number of phases

$N_{s}, N_{r} \quad$ Stator, rotor number of turns in series per phase.

$p \quad$ Number of poles.

$P_{m}, P_{s} \quad$ Mechanical, stator power.

$r_{s}, r_{r} \quad$ Stator, rotor winding mean radius.

$\operatorname{Re}(\cdot) \quad$ Real-part operator.

$R_{s}, R_{r} \quad$ Stator, rotor resistance.

$s \quad$ Slip $\left(\omega_{s}-\omega_{m}\right) / \omega_{s}$.

$T \quad$ Electromagnetic torque.

$\bar{V}_{S} \quad$ Stator voltage phasor.

$X_{l s}, X_{m}, X^{\prime}{ }_{l r}$ Stator leakage, mutual, rotor leakage inductance

$\bar{Z} \quad$ Complex impedance.

$\alpha, \beta \quad$ Stationary axes

$\delta, \Delta \quad$ Linear current distribution, electric loading

$\varepsilon_{s}, \varepsilon_{r} \quad$ Stator, rotor relative pitch shortening.

$\eta \quad$ Efficiency

$\rho \quad$ Winding material resistivity.

$\omega_{m}, \omega_{s} \quad$ Rotor angular speed, stator frequency.

\begin{tabular}{ll}
\multicolumn{3}{c}{ Subscripts and superscripts } \\
$C_{r}, C_{s}$ & IM with both $C_{r} \& C_{s}$, IM with $C_{s}$ only. \\
max, pk & Max of the peak envelope, single peak value \\
$s, r$ & Stator or rotor quantities. \\
$(T)$ & Related to peak torque. \\
$\bar{x}$ & Complex \\
$\underline{x}$ & Complex conjugate \\
$(\eta)$ & Related to peak efficiency
\end{tabular}

\section{INTRODUCTION}

The vast majority of electrical machines are built around a magnetic steel core that forms the magnetic circuit in the machine. This allows the machines to operate at a high magnetic loading for improved torque and power densities. If the magnetic steel core is removed, the magnetic loading reduces significantly and the torque capability of the machine can only be maintained by increasing the electric loading to compensate. Increasing the current loading however is restricted by heating issues but also because the reactance of the machine limits the current for a given voltage.

Air-cored machines have been used in some specialist applications to reduce rotor inertia for example where torque capability is not as important. An axial-flux layout has been proposed for coreless permanent magnet machines to maximize the coupling and interaction between magnets and windings and reduce the requirements for the electrical loading [1]. In air-cored induction machines (IMs), the absence of the iron core causes a large drop in the magnetizing inductance, which then increases the current demand to create the required magnetic loading.

Capacitors resonating with the leakage inductance have been regarded as a possible solution to compensate for the leakage inductance voltage drop and boost the current level without increasing the required rated voltage. This principle has been adopted for long time in wireless energy transfer devices which rely on coils with inherently poor magnetic coupling [3]-[5]. The capacitor resonating with the leakage inductance also creates a tuned filter allowing the system to absorb a sinusoidal current even when fed by a converter with square wave modulation, which helps reducing switching losses [2].

The same concept has recently been proposed for a highspeed, air-cored IM in [6], [7] and [8]. The results in these papers, however, are only based on $2 \mathrm{D}$ steady-state FE simulations at different stator frequencies and slip values for a given machine, and do not provide any insight into the 
optimal values of stator and rotor capacitors as a function of the machine parameters and operating conditions.

This paper uses a steady-state analytical model based on the equivalent circuit of the IM supplemented with stator and rotor capacitors to derive the main operating characteristics of coreless IMs under constant-amplitude voltage supply. The paper provides compact equations for the key parameters such as peak torque and efficiency and related slip values, and derives figures for torque and power densities considering well-established values for current density levels related to standard cooling technologies. A discussion of some of the practical issues of this type of machine is also included.

\section{Modelling}

\section{A. Steady-State Equivalent Circuit}

The equivalent circuit of the considered air-cored machine comes from the standard equivalent circuit of a conventional induction machine with added stator and rotor series capacitors of reactance $X_{C s}$ and $X_{C r}^{\prime}$, as shown in Fig. 1. The referred rotor capacitor reactance $X^{\prime}{ }_{C r}$ is divided by the slip $s$ squared, following the normal transformation of the rotor equation (including a series capacitive reactance) from the rotor frame (slip frequency $s \omega_{s}$ ) into the stator frame (frequency $\omega_{s}$ ) where all the reactances are evaluated at $\omega_{s}$.

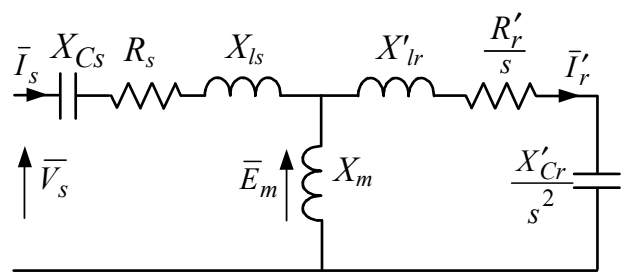

Fig. 1. Equivalent circuit with stator and rotor series capacitors.

All the fundamental expressions for electromagnetic torque and powers in terms of currents are identical to those in the ordinary IM, the only difference being in the impedances needed to evaluate the currents, as summarized in (1)-(2). As the leakage and magnetizing terms in an air-cored machine may have the same order of magnitude, the magnetizing branch cannot be moved across to the terminals. The efficiency in (4) ignores the mechanical losses and assumes litz wires with appropriate strand diameter and transposition to avoid significant eddy losses.

$$
\begin{gathered}
\bar{Z}_{r}^{\prime}=\frac{R_{s}^{\prime}}{s}+j\left(X_{l s}^{\prime}-\frac{X_{C r}^{\prime}}{s^{2}}\right), \quad \bar{Z}_{m r}=\frac{j X_{m} \bar{Z}_{r}^{\prime}}{\bar{Z}_{r}^{\prime}+j X_{m}} \\
\bar{Z}_{t}=R_{s}+j\left(X_{l s}-X_{C s}\right)+\bar{Z}_{m r} \\
\bar{I}_{s}=\frac{V_{s}}{\bar{Z}_{t}}, \bar{I}_{r}^{\prime}=\bar{I}_{s} \frac{\bar{Z}_{m r}}{\bar{Z}_{r}^{\prime}}, T=\frac{m p}{2 \omega_{s}}\left|\bar{I}_{r}^{\prime}\right|^{2} \frac{R_{r}^{\prime}}{s} \\
P_{m}=T \omega_{m} \quad, P_{s}=m \operatorname{Re}\left(V_{s} \underline{I}_{s}\right), \eta_{s}= \begin{cases}P_{m} / P_{s} & \text { mot. } \\
P_{s} / P_{m} & \text { gen. } .\end{cases}
\end{gathered}
$$

The following expressions for the energy stored in the stator and rotor capacitors are used to define the capacitor ratings

$$
E_{C s}=\frac{1}{2} C_{s}\left(X_{C s}\left|\bar{I}_{s}\right|\right)^{2}=\frac{1}{2} \frac{\left|\bar{I}_{s}\right|^{2}}{\omega_{s}^{2} C_{s}},
$$

$$
E_{C r}=\frac{1}{2} C_{r}\left(\frac{X_{C r}}{s}\left|\bar{I}_{r}\right|\right)^{2}=\frac{1}{2} \frac{\left|\bar{I}_{r}\right|^{2}}{\omega_{s}^{2} s^{2} C_{r}}=\frac{1}{2} \frac{\left|\bar{I}_{r}^{\prime}\right|^{2}}{\omega_{s}^{2} s^{2} C_{r}^{\prime}}
$$

\section{B. Parameter Estimation}

The magnetizing inductance of the air-cored IM is expected to be lower than that of ordinary IMs and of the same magnitude as the leakage inductances. These values are calculated using a simple 2D model.

Fig. 2 shows the schematic of the idealized IM cross section, where each three-phase, double-layer rotor or stator winding is represented by two-layer current blocs with total height $h_{r}$ and $h_{s}$, average radius $r_{r}$ and $r_{s}$, and with short pitch factor $\varepsilon_{r}$ and $\varepsilon_{s}$ for rotor and stator respectively. The magnetic axes of rotor and stator "phase a" are denoted with $\alpha_{r}$ and $\alpha_{s}$ respectively, and $g$ depicts the physical air gap. For the estimation of the machine inductances, each two-layer current block is replaced by a current sheet centered on the stator and rotor mean diameters. For a current sheet with $m$ phases and $p$ poles, the linear current distribution is

$$
\delta_{i}(\theta)=\Delta_{i} \sum_{\substack{h=-\infty \\ k=1+2 m h}}^{+\infty} k_{w i k} \sin \left(k \frac{p}{2} \theta\right)
$$

with winding factor $k_{w i k}$ and linear current $\Delta_{i}$ given by

$$
k_{w i k}=k_{d k} k_{p i k} \quad, \quad \Delta_{i}=\frac{m \sqrt{2}}{\pi p} \frac{N_{p i} I_{p i}}{r_{w i}}=\frac{m \sqrt{2}}{\pi} \frac{N_{i} I_{i}}{r_{w i}}
$$

In (7)-(8), subscript " $i$ " stands for " $s$ " (stator) or " $r$ " (rotor).

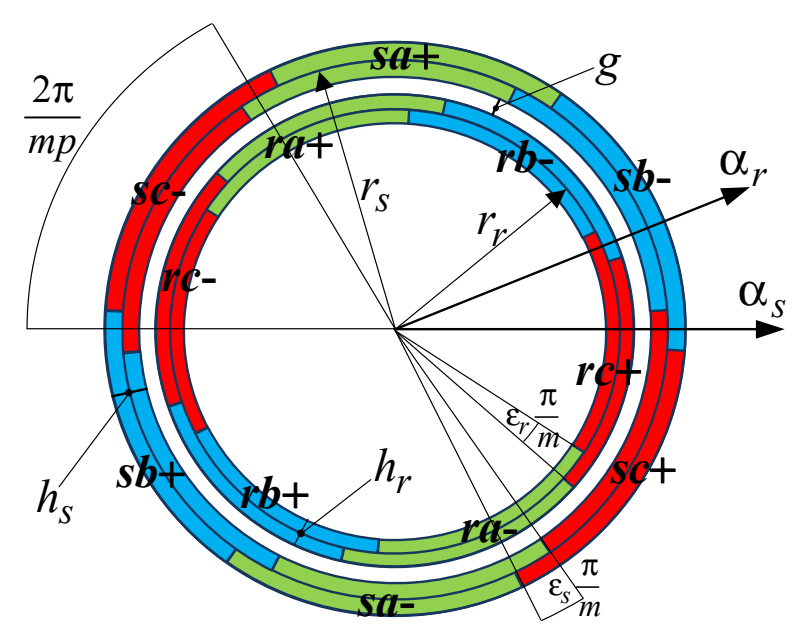

Fig. 2. Idealised cross-section of the air-cored machine (three-phase).

The current sheet model corresponds to having an infinite number of slots per pole-phase $q$ in the stator and rotor, so that distribution factor $k_{d k}$ in (8) for both windings and the generic harmonic of order $k$ equals

$$
k_{d k}=\lim _{q \rightarrow \infty} \frac{\sin \frac{k \pi}{2 m}}{q \sin \frac{k \pi}{2 m q}}=\frac{\sin \frac{k \pi}{2 m}}{\frac{k \pi}{2 m}}
$$

Short pitching is accounted for by pitch factor $k_{p i k}$ 


$$
k_{p i k}=\sin \left(k\left(1-\varepsilon_{i}\right) \frac{\pi}{2}\right) \quad, \quad i=s, r
$$

The well-known 2D analytical solution for the magnetic vector potential from a three-phase current sheet [9], along with appropriate current and geometric parameters of stator and rotor, allows $L_{m}$ to be derived from the mutual flux linkage. Stator and rotor self-inductances $L_{s}$ and $L_{r}^{\prime}$ are calculated from the magnetic energy by energizing either the stator or rotor windings with balanced $m$-phase currents.

$$
\begin{gathered}
L_{m}=\mu_{0}\left(N_{s} k_{w s 1}\right)^{2} \frac{2 m}{\pi p} \ell\left(\frac{r_{r}}{r_{s}}\right)^{p / 2} \\
L_{s}=\mu_{0} \ell \frac{2 m}{\pi p} N_{s}^{2} \sum_{\substack{h=-\infty \\
k=|1+2 m h|}}^{+\infty} \frac{k_{w s k}^{2}}{k} \\
L_{r}^{\prime}=\mu_{0} \ell\left(\frac{k_{w s 1}}{k_{w r 1}} N_{s}\right)^{2} \frac{2 m}{\pi p} \sum_{\substack{h=-\infty \\
k=|1+2 m h|}}^{+\infty} \frac{k_{w r k}^{2}}{k}
\end{gathered}
$$

The leakage inductances follow from the usual definition:

$$
L_{l s}=L_{s}-L_{m} \quad L_{l r}^{\prime}=L_{r}^{\prime}-L_{m}
$$

Symbol $\ell$ in (11)-(13) denotes the axial length of the machine: the contribution of end-windings is neglected, though it is likely to be more important than in cored machines. End-windings are however accounted for in the calculation of stator and rotor resistances and modelled as semi-circles with a diameter equal to the pole span. Expressions for stator and rotor turn mean length $l_{s}$ and $l_{r}$ are

$$
l_{s}=2\left(\ell+\frac{\pi^{2} r_{s}}{p}\right) \quad, \quad l_{r}=2\left(\ell+\frac{\pi^{2} r_{r}}{p}\right)
$$

In a winding with $p$ poles and $a$ parallel paths, and with a cross sectional area of the conductors $A_{c}$, the resistance associated with the $N_{p}$ conductors (all in series) of one stator pole is $R_{s p}=\rho N_{p} l_{s} / A_{c}$. The stator phase resistance $R_{s}$ comprises $(p / 2) / a$ branches " $R_{s p}$ " in series, and then $a$ paths in parallel, resulting in $R_{s}=\left(((p / 2) / / a) R_{s p}\right) / a$. Finally, the cross sectional area of a conductor is related to the winding spread $2 \pi /(m p)$ and depth $h_{s}$ by $N_{p} A_{c}=(2 \pi /(m p)) r_{s} h_{s} k_{f i l l}$, where $k_{\text {fill }}$ is the fill factor. Consequently, the stator and referred rotor resistances are given by

$$
R_{s}=\rho \frac{m N_{s}^{2}}{\pi k_{f i l l}} \frac{l_{s}}{r_{s} h_{s}} \quad, \quad R_{r}^{\prime}=\rho \frac{m N_{s}^{2}}{\pi k_{f i l l}}\left(\frac{k_{w s 1}}{k_{w r 1}}\right)^{2} \frac{l_{r}}{r_{r} h_{r}}
$$

\section{AIR-CORED IM CASE STUDY}

Sections IV and V will derive general formulae for peak efficiency and torque in different scenarios. The quantitative results and characteristics presented, however, will refer to a specific 2-pole, $200 \mathrm{~V}$ (phase), $250 \mathrm{~Hz}$ coreless IM delivering $171 \mathrm{~kW}$ at $16,300 \mathrm{rpm}\left(T_{e}=130 \mathrm{Nm}\right)$ with the parameters listed in Table I. The design is not discussed in full detail here, but was based on the equations given in Section V-B.
The rated operating point was located at peak efficiency slip in the generating mode for full resonance with the stator capacitors only (i.e. no rotor capacitors). The relatively low current density level $\left(5 \mathrm{~A} / \mathrm{mm}^{2}\right)$ resulted in a design with an efficiency of $91 \%$ but relatively high active mass (copper windings) of $313 \mathrm{~kg}$. Further comments on the power density for a second design with the same specs and higher current density $\left(22 \mathrm{~A} / \mathrm{mm}^{2}\right)$ will be given in Section VI. The machine envelope size is: outer diameter $389 \mathrm{~mm}$, total length including end-winding space $585 \mathrm{~mm}$.

TABLE I. AIR-CORED IM RATINGS, PARAMETERS, AND DIMENSIONS

\begin{tabular}{|c|c|c|c|c|c|}
\hline \multicolumn{7}{|c|}{ Ratings } \\
\hline$V_{s n}$ & $(\mathrm{~V})$ & 200 & $I_{s n}$ & $(\mathrm{~A})$ & 243.7 \\
\hline$\omega_{s n}$ & $(\mathrm{rad} / \mathrm{s})$ & $2 \pi \times 250$ & $n$ & $(\mathrm{rpm})$ & 15,407 \\
\hline$P_{s n}$ & $(\mathrm{~kW})$ & 171.1 & $s_{n}$ & - & -0.02727 \\
\hline$T_{e n}$ & $(\mathrm{Nm})$ & 100 & $\eta_{p k}$ & - & 0.9061 \\
\hline \multicolumn{7}{|c|}{ Equivalent circuit parameters } \\
\hline$R_{s}$ & $(\Omega)$ & 0.06110 & $R_{r}^{\prime}$ & $(\Omega)$ & 0.114488 \\
\hline$X_{l s}$ & $(\Omega)$ & 0.564498 & $X_{l r}^{\prime}$ & $(\Omega)$ & 0.564498 \\
\hline$X_{m}$ & $(\Omega)$ & 2.34182 & $C_{s}$ & $(\mu \mathrm{F})$ & 277.0 \\
\hline$V_{C s}$ & $(\mathrm{~V})$ & 559.9 & $E_{C s}$ & $(\mathrm{~kJ})$ & 43.4 \\
\hline \multicolumn{7}{|c|}{ Dimensions and winding data } \\
\hline$r_{s}$ & $(\mathrm{~mm})$ & 174.7 & $r_{r}$ & $(\mathrm{~mm})$ & 140.8 \\
\hline$h_{s}$ & $(\mathrm{~mm})$ & 39.3 & $h_{r}$ & $(\mathrm{~mm})$ & 22.3 \\
\hline$\ell$ & $(\mathrm{mm})$ & 310 & $g$ & $(\mathrm{~mm})$ & 3.12 \\
\hline$N_{s}$ & - & $\approx 74$ & $N_{r}$ & - & $\approx 74$ \\
\hline
\end{tabular}

\section{PERFORMANCES WITH STATOR AND ROTOR CAPACITORS}

The current and torque characteristics are deeply affected by the presence of the stator and rotor capacitors $C_{s}$ and $C_{r}$. This section presents the relationships for peak torque and efficiency under the assumption of a voltage-driven stator and with both stator and rotor capacitors in place. A few comments are given on the main aspects of operation with a current-driven stator, which would lead to a sensibly different behavior. The performance using only stator capacitors is discussed in Section V.

The derivation of torque and efficiency characteristics requires convolute algebraic manipulations which have been carried out with Wolfram-Mathematica ${ }^{\circledR}$ software package.

\section{A. Peak torque at stator resonance}

When both the stator and rotor capacitors are in place, the stator capacitor should be tuned to resonate at the rated frequency with the stator leakage inductance so as to reduce stator voltage ratings for a given current.

$$
X_{C s}=X_{l s} \Rightarrow C_{s}=\frac{1}{\omega_{s}^{2} L_{l s}}
$$

Noting the rotor capacitive reactance in Fig. 1 is divided by $s^{2}$, the rotor capacitor value $C_{r}$ can be selected to achieve resonance and then maximum rotor current at a generic prescribed slip. Intuitively, this will also determine the peak torque. Equating the derivative of torque to zero with respect to slip and solving with respect to $X_{C r}^{\prime}$ gives the capacitive rotor reactance $X_{C r}^{\prime}(T)$ required to make the torque maximum at a given slip $s$.

$$
\frac{\partial T\left(s, X_{C r}^{\prime}\right)}{\partial s}=0 \quad \Rightarrow \quad X_{C r}^{\prime(T)}=X_{C r}^{\prime(T)}(s)
$$

The expression of $X^{\prime}{ }_{C r}^{(T)}(s)$ is given in (19) at the bottom of 
the page. For stator and rotor resistances assumed negligible with respect to reactances $\left(R_{s}, R_{r}^{\prime}<<X_{l s}, X_{l r}^{\prime}, X_{m}\right),(19)$ becomes

$$
X_{C r}^{\prime(T)}(s) \approx X_{C r}^{\prime(r e s)}(s)=s^{2} X_{l r}^{\prime}
$$

Under the assumption $R_{s} \& R_{r}^{\prime}<<X_{m}$, the corresponding peak torque envelope is

$$
T_{p k}(s) \approx \frac{m p V_{s}^{2}}{2 \omega_{s}} \frac{s R_{r}^{\prime} X_{m}^{2}}{s^{2} R_{s}^{2} X_{m}^{2}+2 s R_{s} R_{r}^{\prime} X_{m}^{2}+R_{r}^{\prime 2}\left(R_{s}^{2}+X_{m}^{2}\right)}
$$

However, the simplified expression (20) for the optimal rotor capacitor reactance $X^{\prime}{ }_{C r}{ }^{(T)}(s)$ for maximum torque holds only if the desired slip value for maximum torque is not too small, because otherwise the radicand in (19) becomes negative. This is expected, since the slope of the electromagnetic torque is zero at synchronism and the torque needs some slip to ramp up and reach the peak value. In other words, at small slip values - depending on the parameters, (20) only enforces resonance in the rotor but it does not necessarily guarantee maximum torque.

It must be noticed that (21) does not represent a single torque versus slip characteristic but rather the envelope of the peaks of all the torque characteristics. In the light of that, maximizing (21) provides the values of maximum motoring and generating peak torques $T_{p k}^{\max }$ and the corresponding slip values $s_{T p k}^{\max }$ in (22) and (23), where $+/$ - are for motoring and generating modes respectively.

$$
\begin{array}{r}
\max _{T p k} \approx \pm \frac{R_{r}^{\prime} \sqrt{R_{s}^{2}+X_{m}^{2}}}{R_{s} X_{m}} \approx \pm \frac{R_{r}^{\prime}}{R_{s}} \\
T_{p k}^{\max } \approx \frac{m p V_{s}^{2} X_{m}^{2}}{4 \omega_{s} R_{s}^{3}}\left(-1 \pm \sqrt{1+\frac{R_{s}^{2}}{X_{m}^{2}}}\right) \approx\left\{\begin{array}{l}
\frac{m p V_{s}^{2}}{8 \omega_{s} R_{s}} \text { mot. } \\
-\frac{m p V_{s}^{2} X_{m}^{2}}{2 \omega_{s} R_{s}^{3}} \text { gen. }
\end{array}\right.
\end{array}
$$

Equations (22)-(23) show that when both the stator and rotor leakage inductances resonate with the stator and rotor capacitors the maximum peak torque is resistance-limited but may occur at slip values higher than unity, i.e. in the braking region. This happens if the stator and rotor are designed for the same current density, leading to $R_{S}<R_{r}^{\prime}$. Fig. 3 shows the stator and rotor current, torque and efficiency versus slip characteristics for the air-cored IM with parameters in
Table I using different rotor capacitor values and operating at rated voltage of $200 \mathrm{~V}$. The stator capacitor value is tuned with (17) and rotor capacitor values are tuned with (19) in order to locate the peak torque value at slip values $s= \pm 0.2$, $\pm 0.3, \pm 0.4, \pm 0.5$. The peak torque envelope (21) is plotted on the same figure. With the considered parameters, the minimum slip values which can be put into (19) are $s=$ \pm 0.174 and represent the minimum achievable slip magnitude for peak torque points, due to the zero slope of the torque curves at $s=0$. The minimum value $s=0.174$ is quite high as the consequence of rotor resistance being significantly high when compared to the leakage reactances.
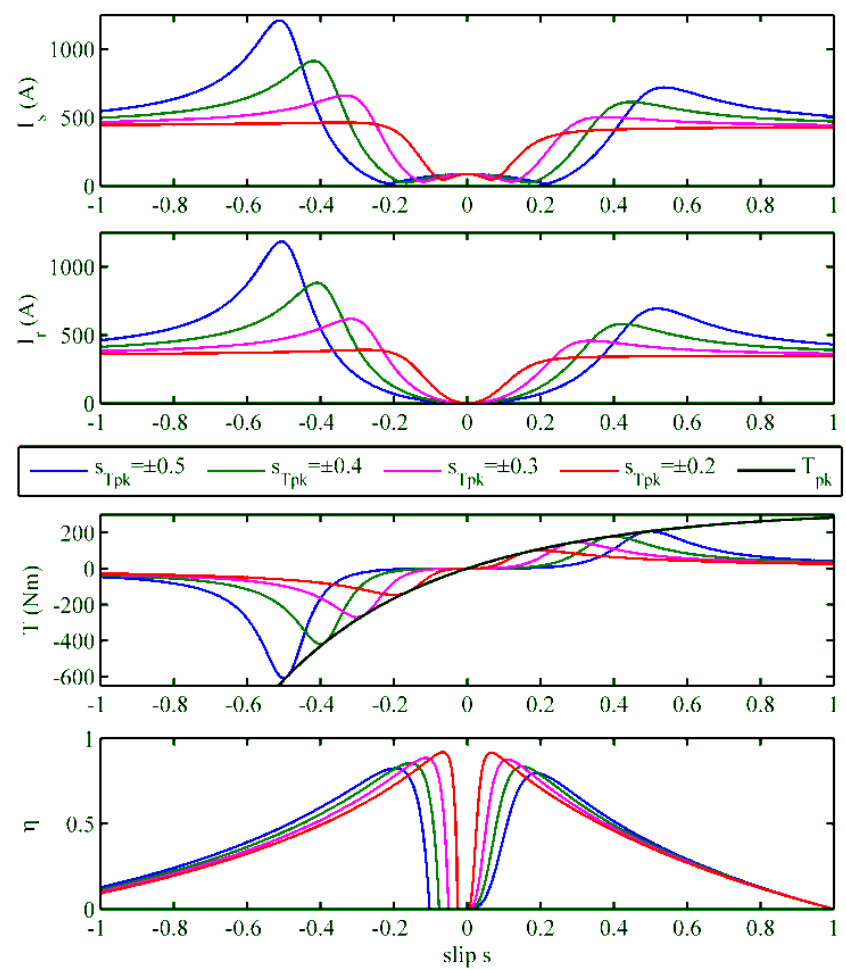

Fig. 3. Stator and rotor current, torque and efficiency vs slip characteristics with stator and rotor capacitors tuned according to (17) and (19) to locate the peak torque at $s= \pm 0.2, \pm 0.3, \pm 0.4, \pm 0.5$. The $T_{p k}$ curve refers to the peak torque envelope (21).

As expected, the efficiency at the peak torque slip is significantly lower than the peak efficiency, especially if the peak torque slip is high. This happens because at negative slips the term $R_{r}^{\prime} / s$ reduces the overall terminal resistance.

Furthermore, the peak current and torque in generating mode are higher than the corresponding values in motoring mode. The sharpness of the torque characteristic depends mainly on the value of the rotor resistance. Its role is illustrated in Fig. 4 , which refers to the rotor capacitor design locating the peak torque at slip values $s= \pm 0.2$ (red characteristic in Fig. 3-c).

$$
\begin{aligned}
& X_{C r}^{\prime(T)}(s)= \\
& s \frac{s\left(X_{m}^{2} X_{l r}^{\prime}+R_{s}^{2}\left(X_{m}+X_{l r}^{\prime}\right)\right)+\sqrt{s^{2}\left(4 X_{m}^{4} X_{l r}^{\prime 2}+4 R_{s}^{4}\left(X_{m}+X_{l r}^{\prime}\right)^{2}+R_{s}^{2} X_{m}^{2}\left(3 X_{m}^{2}+8 X_{l r}^{\prime}\left(X_{m}+X_{l r}^{\prime}\right)\right)\right)-3 R_{r}^{\prime 2}\left(R_{s}^{2}+X_{m}^{2}\right)^{2}}}{3\left(R_{s}^{2}+X_{m}^{2}\right)}
\end{aligned}
$$




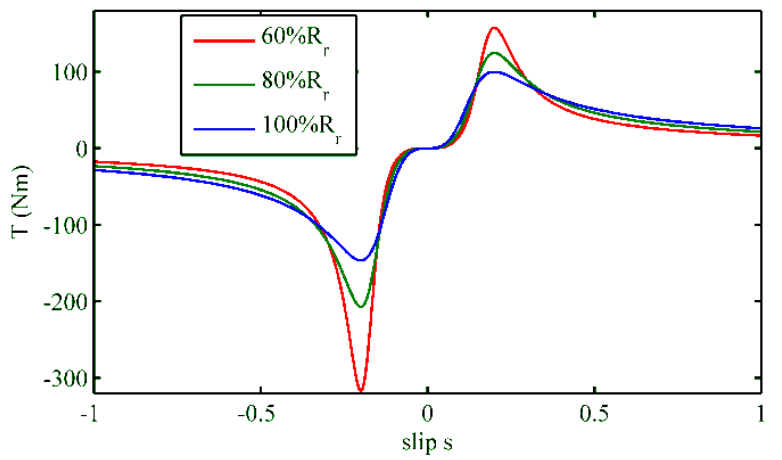

Fig. 4. Effect of rotor resistance $R_{r}$ on the torque characteristic when stator and rotor capacitors tuned according to (17) and (19) to locate the peak torque at $s= \pm 0.2$ with different $R_{r}$ values.

Fig. 5 shows the voltage magnitude across the stator and rotor capacitors and the energy stored in the capacitors: the rotor capacitor voltage is referred to the rotor (slip) frequency. These values depend on the operating point and slip selected for the peak torque to occur. If the IM is to operate within the full slip range, the capacitor ratings should be selected according with the peak current and voltage values.

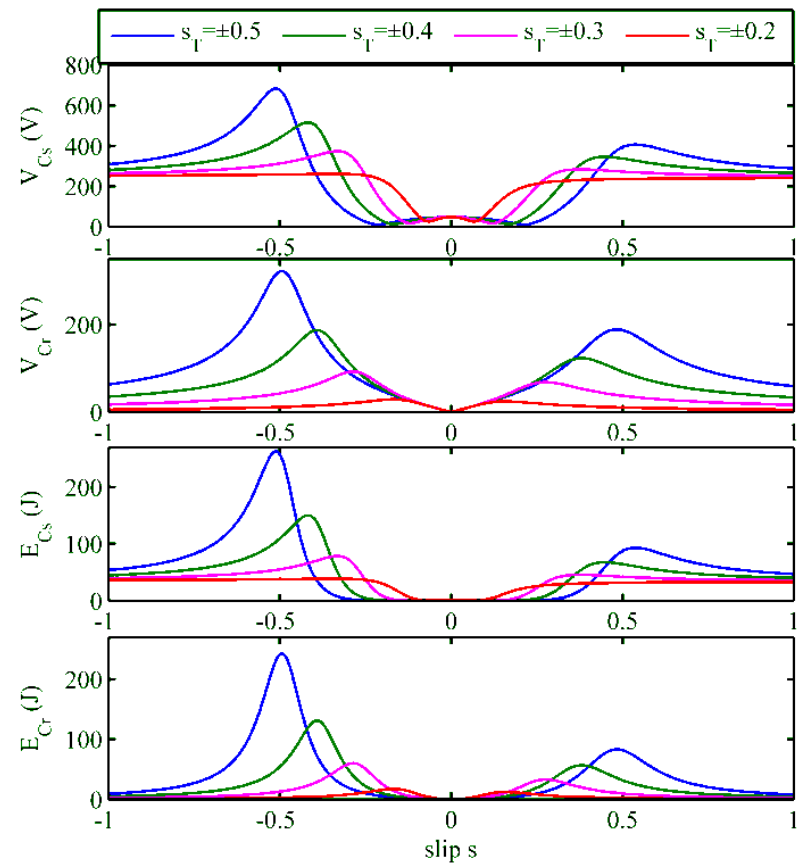

Fig. 5. Stator and rotor capacitor voltage and energy, when they are tuned according to (17) and (19) to locate the peak torque at $s= \pm 0.2, \pm 0.3, \pm 0.4$, \pm 0.5 .

As an example, if the aircored IM has to deliver peak torque at $s= \pm 0.2$, the stator and rotor capacitor ratings as read in Figs. 3 and 5 would be $\{261 \mathrm{~V}, 462.5 \mathrm{~A}, 38.5 \mathrm{~J}\}$ and $\{28.7$ $\mathrm{V}, 390.8 \mathrm{~A}, 17.5 \mathrm{~J}\}$, with $C_{r}=42.5 \mathrm{mF}$. Assuming a typical energy density for typical film capacitors around $16 \mathrm{~J} / \mathrm{kg}$ (from datasheets), these ratings correspond to approximatively $10 \mathrm{~kg}$ of extra weight for the capacitors. It is worth mentioning that in the case of constant-magnitude stator current supply, the approximate condition (20) for maximum torque would include total rotor self-inductance $\left(X_{m}+X_{l r}^{\prime}\right)$ instead of leakage component $X_{l r}^{\prime}$ only.

\section{$B$. Operation at permanent rotor resonance, peak efficiency}

Fig. 6 shows the stator and rotor current, torque and efficiency characteristics versus slip with the stator capacitors tuned according to (17) and when the rotor capacitors are adjusted with slip according to (20), in order to maintain the rotor at resonance at every slip. The torque characteristic corresponds roughly to (21), i.e. to the black curve in the third subplot of Fig. 3. The maxima predicted by (21) occur at $s_{T p k}= \pm 1.873$ which falls outside the operational slip range. The maximum peak torque in generating mode is much higher than the maximum peak motoring torque, because of the increase in the stator current caused by the negative term $R_{r}{ }^{\prime} / s$ as already discussed for Figs. and 3 and 4 . Nonetheless, the terminal reactance and terminal impedance magnitude remain positive, unlike the scenario discussed in Section V-C.
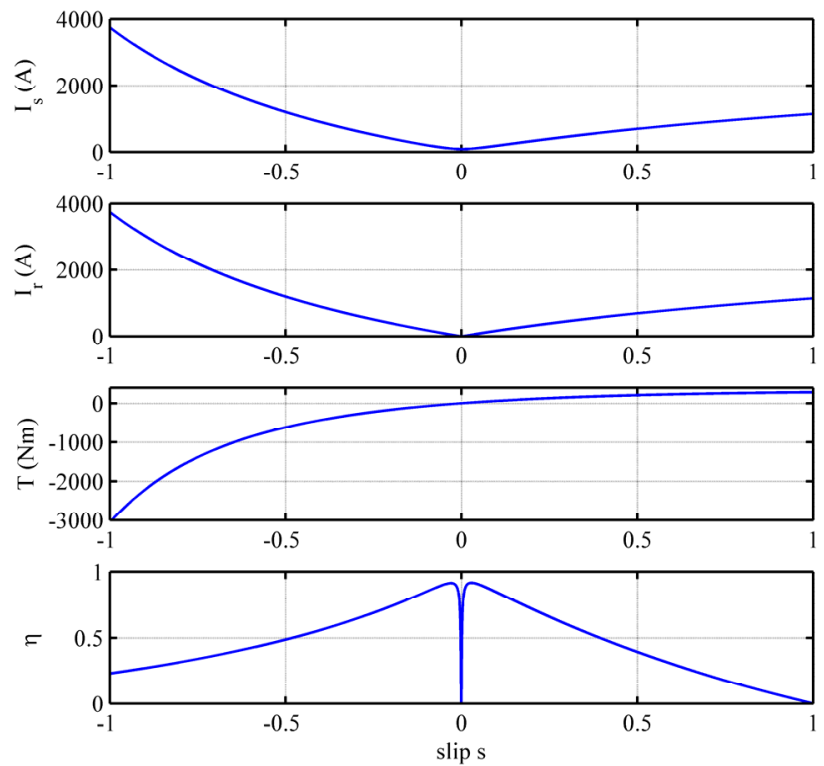

Fig. 6. Stator and rotor current, torque and efficiency vs slip characteristics when stator and rotor are maintained at resonance at every slip value, according to (17) and (20).

The stator capacitors do not impact on the efficiency because they only affect the voltage ratings. Assuming that the rotor is permanently at resonance - i.e. with $X_{C r}^{\prime}$ in (20), the slip value which maximizes efficiency (4) is found from:

$$
\begin{aligned}
& \frac{\partial \eta\left(s, X_{C r}^{\prime}=X_{C r}^{\prime r e s}(s)\right)}{\partial s}=0 \quad \Rightarrow \\
& s_{C r}^{(\eta)}=\frac{-R_{s} R_{r}^{\prime} \pm \sqrt{R_{s}\left(R_{s} R_{r}^{2}+X_{m}^{2}\left(R_{s}+R_{r}^{\prime}\right)\right)}}{X_{m}^{2}\left(R_{s}+R_{r}^{\prime}\right) / R_{r}^{\prime}} \approx \pm \frac{R_{r}^{\prime}}{X_{m}} \sqrt{\frac{R_{s}}{R_{s}+R_{r}^{\prime}}}
\end{aligned}
$$

with +/- for motoring/generating mode respectively. The resulting expressions for the peak efficiency are in (25).

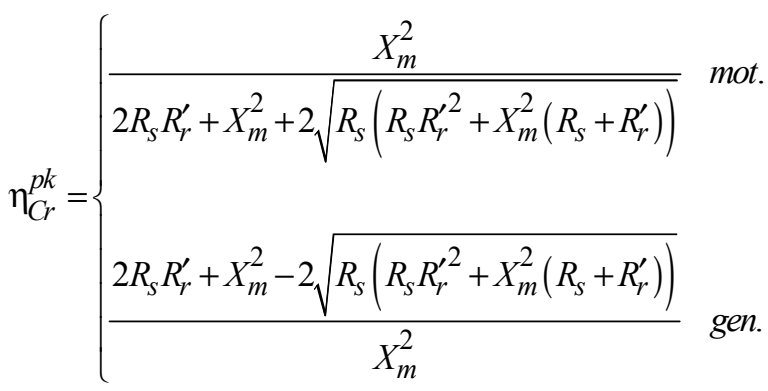


When $X_{m}$ dominates over $R_{s}$ and $R_{r}^{\prime},(25)$ becomes

$$
\eta_{C r}^{p k} \approx\left\{\begin{array}{cc}
\frac{X_{m}}{X_{m}+2 \sqrt{R_{s}\left(R_{s}+R_{r}^{\prime}\right)}} & \text { mot. } \\
\frac{X_{m}-2 \sqrt{R_{s}\left(R_{s}+R_{r}^{\prime}\right)}}{X_{m}^{2}} & \text { gen. }
\end{array}\right.
$$

\section{PERFORMANCES WITH STATOR CAPACITORS ONLY}

\section{A. Overview}

Fitting the capacitors in the rotor may be impractical because of limited space. With no rotor capacitors and at moderate slip, the rotor current will be limited by the uncompensated rotor leakage inductance. Equations (1)-(4) remain valid to describe this case, under the limit $X_{C r}^{\prime} \rightarrow \infty\left(C_{r} \rightarrow 0\right)$. In such a scenario, the stator capacitor may be tuned in order to resonate at the rated frequency with the equivalent inductance seen from the stator terminals, and in the attempt to minimize the terminal impedance and boost the stator current. If $X_{C r}^{\prime} \rightarrow \infty$, the terminal impedance $\bar{Z}_{t}=R_{t}+j X_{t}$ in (2) has the following components

$$
\begin{gathered}
R_{t}=R_{s}+\frac{s X_{m}^{2} R_{r}^{\prime}}{R_{r}^{\prime 2}+s^{2}\left(X_{m}+X_{l r}^{\prime}\right)^{2}} \\
X_{t}=-X_{C s}+ \\
\frac{\left(X_{m}+X_{l s}\right) R_{r}^{\prime 2}+\left(X_{m}+X_{l r}^{\prime}\right)\left(X_{l s} X_{l r}^{\prime}+X_{m}\left(X_{l s}+X_{l r}^{\prime}\right)\right) s^{2}}{R_{r}^{\prime 2}+s^{2}\left(X_{m}+X_{l r}^{\prime}\right)^{2}}
\end{gathered}
$$

which obviously depend on slip $s$. Resonance can be enforced at any particular slip value by setting $X_{C s}$ in such a way as to have $X_{t}=0$ in (28), so the overall Thevenin impedance will be purely resistive and equal to (27).

Fig. 7 presents the stator and rotor current, torque and efficiency versus slip characteristics for the air-cored IM with parameters in Table I, no rotor capacitors (i.e. $X_{C r}^{\prime} \rightarrow \infty$ ) and operating at rated voltage of $200 \mathrm{~V}$ using different stator capacitor values. These are tuned in order to achieve resonance (i.e. zero $X_{t}(28)$ ) at slip values $s= \pm 0.025, \pm 0.05$, $\pm 0.075, \pm 0.1$. Due to the absence of the rotor capacitors, the characteristics retain the usual shape expected for an ordinary IM. At synchronism, the torque characteristics cross the zero value with positive slope, instead of that shown in Fig. 3. This allows the peak torque to be achieved at very low slip values, depending on $X_{C S}$. As anticipated, the efficiency does not depend on $X_{C S}$, so we have a unique curve in the last subplot of Fig. 7. In general, the selected slip magnitude for resonance to occur does not correspond to the slip value for peak torque.

Achieving resonance at the stator terminals does not maximize the stator current nor does it produce peak torque. This apparent contradiction can be explained by the fact that at resonance the terminal impedance reduces to the terminal resistance $R_{t}(27)$, which is independent of $C_{s}$ and has its own trend with $s$ - very similar to that of torque in Fig. 7 . The expressions for the peak torque and corresponding slip in terms of $C_{s}$ are quite convoluted so are not given here.
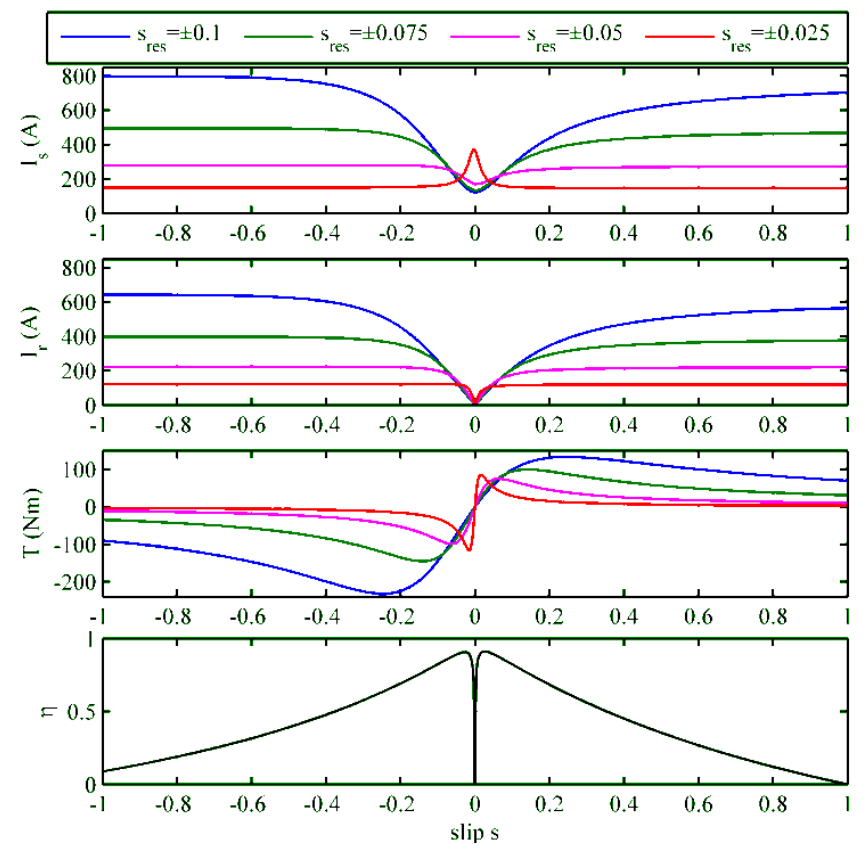

Fig. 7. Stator and rotor current, torque and efficiency vs slip characteristics with stator capacitors only, tuned to have resonance (i.e. zero terminal reactance (28)) at $s= \pm 0.025, \pm 0.05, \pm 0.075, \pm 0.1$.

The voltage across the stator capacitor and the stored energy versus slip characteristics are shown in Fig. 8. In absence of rotor capacitors, the stator capacitors have to compensate the full terminal reactance at the prescribed slip and require bigger ratings than in Fig. 5.

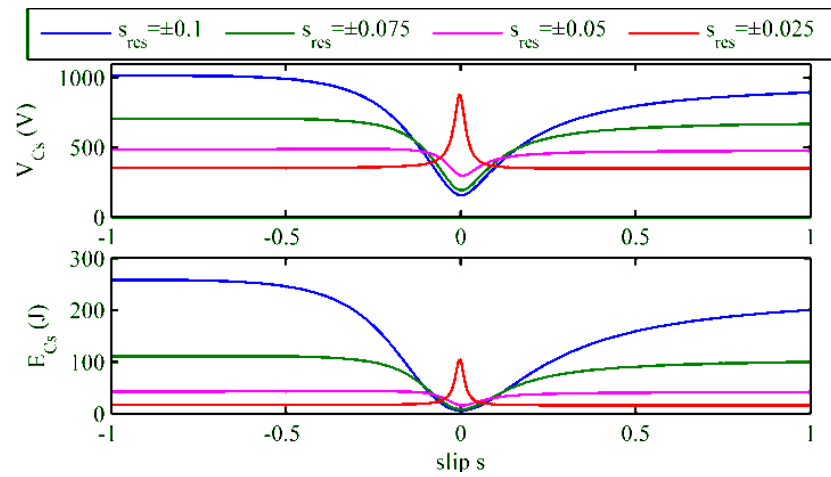

Fig. 8. Stator capacitor voltage drop and stored energy vs slip characteristics with stator capacitors only, tuned to have resonance (i.e. zero terminal reactance (28)) at $s= \pm 0.025, \pm 0.05, \pm 0.075, \pm 0.1$.

\section{B. Maximum efficiency conditions}

Among the infinite possible choices for $s$ at which to enforce resonance with stator capacitors, the most interesting one is the value $s=s \eta$ which maximizes efficiency. This slip value is independent of $X_{C s}$ and is derived from the fundamental equations (1)-(4) as follows

$$
\begin{aligned}
& \frac{\partial \eta\left(s, X_{C r}^{\prime} \rightarrow \infty\right)}{\partial s}=0 \Rightarrow \\
& s_{C s}^{(\eta)}=\frac{R_{S} R_{r}^{\prime}}{R_{s} R_{r}^{\prime} \pm \sqrt{R_{S}\left(R_{S} R_{r}^{\prime 2}+X_{m}^{2} R_{r}^{\prime}+R_{s}\left(X_{m}+X_{l r}^{\prime}\right)^{2}\right)}}
\end{aligned}
$$

where sign + and - are for motoring and generating mode respectively. The resulting peak efficiency for motoring and generating modes is 


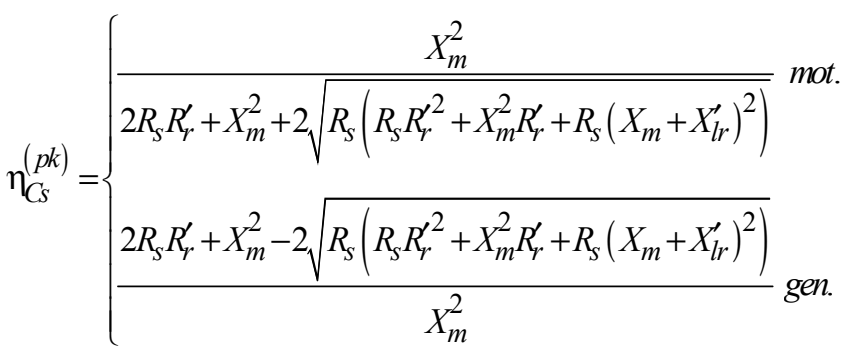

Comparing (29)-(30) with (24)-(25) shows the effect of the uncompensated $X_{l r}^{\prime}$, which was absent in (24)-(25) because it was cancelled by rotor capacitors.

When $X_{C s}$ is selected from (28) to have resonance (i.e. $X_{i}=0$ ) at $s=s_{\eta}(29)$, the corresponding electromagnetic torque is

$$
T_{C s}^{(\eta)}=\frac{m p V_{s}^{2}}{2 \omega_{s}} \frac{s_{\eta} R_{r}^{\prime} X_{m}^{2}\left(R_{r}^{\prime 2}+s_{\eta}^{2}\left(X_{m}+X_{l r}^{\prime}\right)^{2}\right)}{\left(R_{s}\left(R_{r}^{\prime 2}+s_{\eta}^{2}\left(X_{m}+X_{l r}^{\prime}\right)^{2}\right)+s_{\eta} R_{r}^{\prime} X_{m}^{2}\right)^{2}}
$$

Equations (29)-(31) are useful at the design stage in order to optimize geometric and winding data for given torque and speed demands, assuming that the rated point is to be located at peak efficiency and resonance. This was the approach adopted to design the machine in Table I. This machine was designed to be resonant at the slip value for maximum efficiency in generating mode $(s=s \eta=-0.0272$ from (29)), its characteristics are very close to the red curves in Figs. 7 and 8 and result in the following stator capacitor ratings: $277.0 \mu \mathrm{F}, 559.9 \mathrm{~V}, 243.7 \mathrm{~A}$. Assuming an energy density of $16 \mathrm{~J} / \mathrm{kg}$, the total mass of capacitors is $8.1 \mathrm{~kg}$.

\section{Permanent terminal resonance and zero impedance slip}

In principle, the stator capacitors may be constantly adjusted with slip in order to maintain the terminal impedance at resonance, which means $X_{t}=0$ in (28) for every slip $s$. Although such a scenario is impractical, it helps understand the performance and limits of the air-cored IM. At resonance, $\bar{Z}_{t}$ reduces to $R_{t}$ in (27), and this is zero for two particular negative values of the slip

$$
s_{C s}^{(Z t=0)}=\frac{-X_{m}^{2} R_{r}^{\prime} \pm R_{r}^{\prime} \sqrt{X_{m}^{4}-4 R_{s}^{2}\left(X_{m}+X_{l r}^{\prime}\right)^{2}}}{2 R_{S}\left(X_{m}+X_{l r}^{\prime}\right)^{2}}
$$

When the slip equals $s_{C S}{ }^{(Z t=0)}$ in (32), stator and rotor currents become infinite and so does the torque. In reality, no capacitors would clearly be able to withstand an infinite current, so the infinite torque cannot be produced and, in order to avoid current surge, critical slip values (32) must never be approached when operating at resonance. This aspect is peculiar to the generating mode and has to be considered when designing the resonant coreless IM generator for operation with variable slip. Fortunately, the slip for maximum efficiency (29) is generally sufficiently far away from the critical values in (32).

Fig. 9 presents the stator and rotor current, torque and efficiency characteristics versus slip when the stator capacitors are adjusted with slip in order to keep $X_{t}=0$ in (28) for every slip. To improve the readability, the explored slip range is limited to $(-0.4,1)$. With the parameters in Table I, the critical slip values (32) for zero terminal impedance are 0.0013 and -1.2152 . The negative torque asymptote at slip $s$
$=-0.0013$ is clearly visible in Fig. 9 whereas that for $s=-$ 1.2152 falls outside the plot range, though the growing trend of currents for negative slip is well apparent.
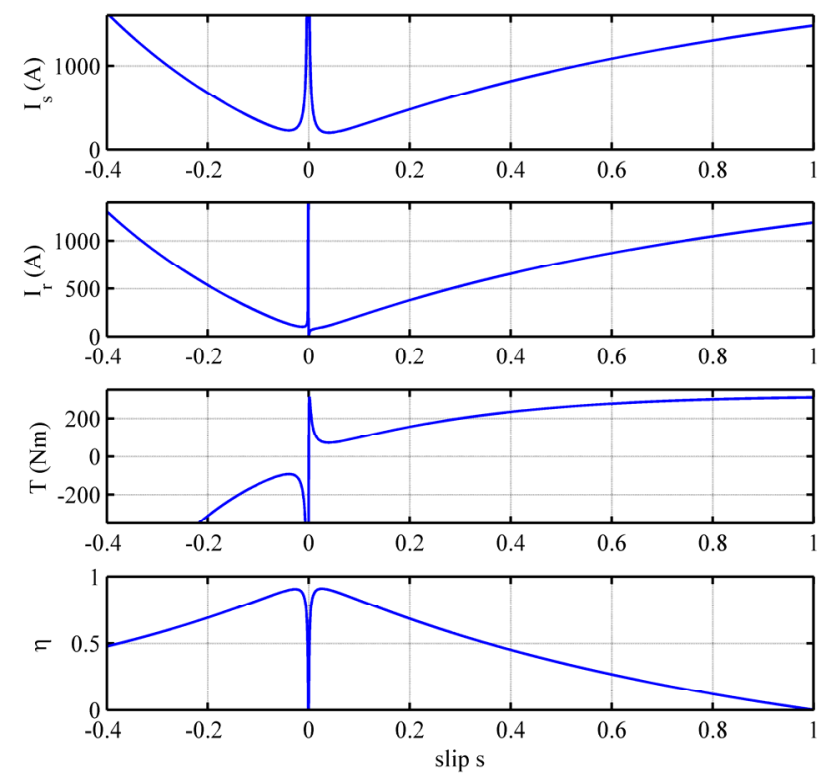

Fig. 9. Stator and rotor current, torque and efficiency vs slip characteristics with stator capacitors only, tuned with slip to have resonance (i.e. zero terminal reactance (28)) at every slip value.

The trends for the required capacitance, associated voltage drop and energy are plotted in Fig. 10: the torque asymptotes correspond to infinite voltage and energy in the capacitors.
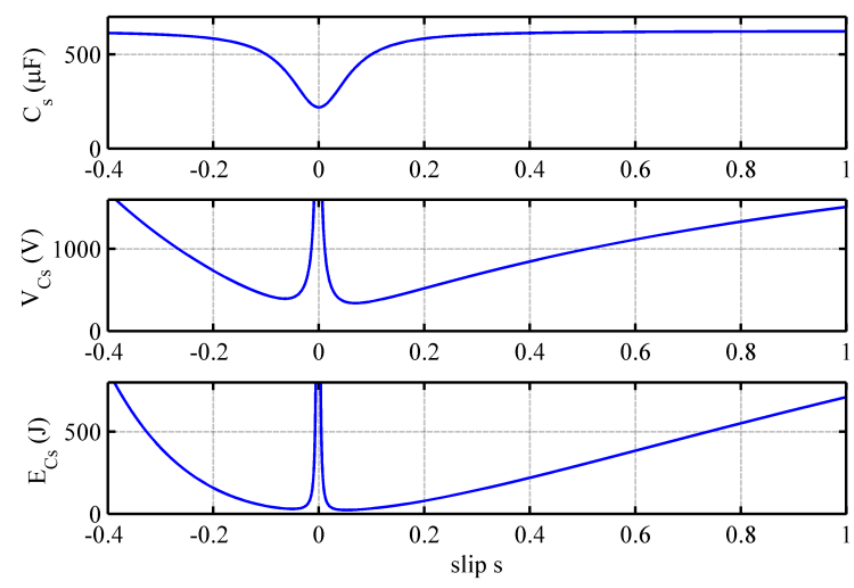

Fig. 10. Stator capacitor voltage drop and stored energy vs slip characteristics with stator capacitors only, tuned to have resonance (i.e. zero terminal reactance (28)) at every slip value.

\section{COMPARISON AND DISCUSSION}

To summarize the performance of air-cored IM's and give a clear idea of the impact of capacitors on torque production, Fig. 11 plots the parametric loci torque vs efficiency with different capacitor configurations and tuning as listed below:

- With no capacitors - black curves

- With stator and rotor capacitors enforcing resonance at any slip value, according to (17) and (20) - blue curves

- With stator capacitor only, tuned to cancel only the stator leakage inductance, i.e. setting $X_{C S}=X_{l s}$ - green curves

- With stator capacitor only, and enforcing resonance at every slip value, i.e. setting $X_{C S}$ to make (28) zero - red curves

The stator voltage and frequency are at the rated value of $200 \mathrm{~V}$ and $250 \mathrm{~Hz}$. 
These curves are obtained with a variable slip spanning the range $(-3,1)$, though the plot range for torque is restricted to $\pm 320 \mathrm{Nm}$ to cut out the singularities (32) and allow better visualization. Points "A" in Fig. 11 represent peak efficiency operating conditions from (26) with stator and rotor capacitors at resonance - according to (17) and (20). Points "B" refer to peak efficiency operation from (30), at resonance with only stator capacitors - i.e. with $X_{t}=0$ in (28): point "B" on the left hand-side is the rated operating point for the aircored IM design in Table I. Point " $\mathrm{C}$ " is the maximum torque point in motoring operation with only stator capacitors and at resonance, i.e. $X_{t}=0$ in (28). The presence of capacitors moves the maximum torque nose to the right but does not affect the peak efficiency level (point A and B) significantly. With no capacitors at all (black curves), the maximum torque collapses because the machine impedance does not allow enough current to flow. Using only stator capacitors tuned to cancel the stator leakage inductance (green curve) boosts the torque but does not beat the solution with rotor capacitors cancelling the rotor leakage too. Surprisingly, the configuration with only stator capacitors tuned to have $X_{t}=0$ in (28) produces more torque than the configuration with stator and rotor capacitors.

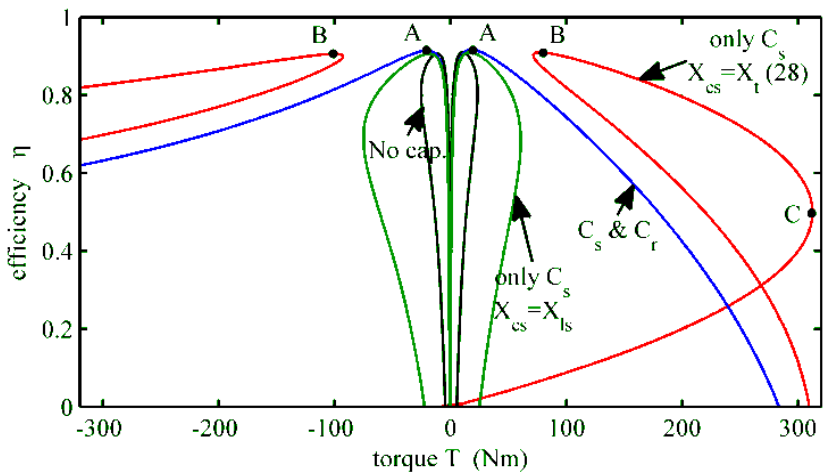

Fig. 11. Parametric loci efficiency versus torque with different capacitor arrangements for the coreless IM in Table I. Black line = no capacitors, blue line $=$ stator and rotor capacitor tuned to have resonance for every slip value (i.e. with (17) and (20)), green line = only stator capacitors, tuned to cancel the stator leakage (see (17)); red line = only stator capacitors, tuned to have terminal resonance at every slip value (i.e. with $X_{t}=0$ in (28)).

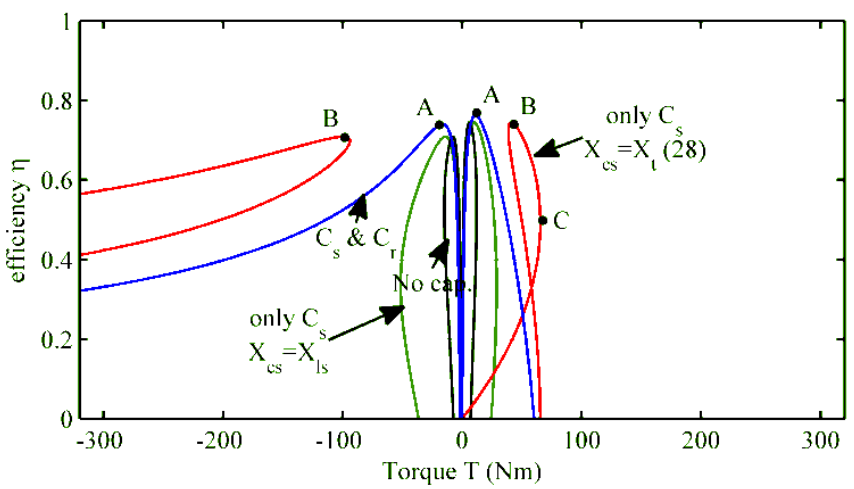

Fig. 12. Parametric loci efficiency versus torque with different capacitor arrangements for a coreless IM design with the same specs in Table I but higher current and power density $\left(22 \mathrm{~A} / \mathrm{mm}^{2}, 3.15 \mathrm{~kW} / \mathrm{Kg}\right.$ to active mass) . Black line $=$ no capacitors, blue line $=$ stator and rotor capacitor tuned to have resonance for every slip value (i.e. with (17) and (20)), green line = only stator capacitors, tuned to cancel the stator leakage (see (17)); red line $=$ only stator capacitors, tuned to have terminal resonance at every slip value (i.e. with $X_{t}=0$ in (28)).

Fig. 12 plots the efficiency vs torque loci for an air-cored IM design with the same specs of Table I (notice that the torque level of point $\mathrm{B}$ on the left-hand side, i.e. $-100 \mathrm{Nm}$, is identical in Figs 11 and 12), but with much higher current and power to active mass densities $\left(22 \mathrm{~A} / \mathrm{mm}^{2}\right.$ and 3.2 $\mathrm{kW} / \mathrm{kg}$ corresponding to $53 \mathrm{~kg}$ of active mass). Torque and efficiency exhibit the same features already illustrated in Fig. 11, although efficiency levels are significantly lower due to the higher current density. Also, the torque capability in motoring operation drops substantially, but it should be noticed that the design is optimized for the generating mode. The total capacitor mass for this design is $8.3 \mathrm{~kg}$.

In the light of Figs 11 and 12, the solution with only stator capacitors tuned to cancel the whole terminal reactance at a prescribed slip (e.g. for peak efficiency) looks the most promising one for simplicity, torque density and efficiency. Conversely, using both rotor and stator capacitors requires high-capacitance rotor capacitors (see end of Sect IV-A).

There are however some issues worthy of consideration:

- The capacitors required are high-energy capacitors with a high current handling capability, which result in increased mass for the overall system

- in generating mode with capacitors tuned to cancel the total reactance $X_{t}$, care should be taken not to approach critical slips (32) causing catastrophic current surges.

\section{CONCLUSION}

This paper explores the concept of an air-cored resonant IM. In a conventional air-cored machine, the magnetic loading collapses along with the torque. In a resonant air-cored machine, the torque can be recovered using resonance which effectively removes one of the barriers to increasing the electrical loading by reducing the machine impedance at resonance. Thermal management however remains an issue.

Among the possible capacitor configurations, the solution with only stator capacitors tuned to cancel the overall terminal reactance looks like the best option for simplicity, low capacitor size, efficiency and torque production.

\section{REFERENCES}

[1] J. F. Gieras and I. A. Gieras, "Performance analysis of a coreless permanent magnet brushless motor," Conference Record of the 2002 IEEE Industry Applications Conference. 37th IAS Annual Meeting, Pittsburgh, PA, USA, 2002, pp. 2477-2482 vol.4.

[2] J. Hou, Q. Chen, S. C. Wong, C. K. Tse and X. Ruan, "Analysis and Control of Series/Series-Parallel Compensated Resonant Converter for Contactless Power Transfer," in IEEE Journal of Emerging and Selected Topics in Power Electronics, vol. 3, no. 1, pp. 124-136, March 2015.

[3] S. Valtchev, B. V. Borge, K. Brandisky and J. B. Klaassens, "Efficient Resonant Inductive Coupling Energy Transfer Using New Magnetic and Design Criteria," 2005 IEEE 36th Power Electronics Specialists Conference, Recife, 2005, pp. 1293-1298.

[4] D. A. G. Pedder, A. D. Brown and J. A. Skinner, "A contactless electrical energy transmission system," in IEEE Transactions on Industrial Electronics, vol. 46, no. 1, pp. 23-30, Feb 1999.

[5] A. Kurs, A. Karalis, R. Moffatt, J.D. Joannopoulos, P. Fisher, M. Soljačić, "Wireless Power Transfer via Strongly Coupled Magnetic Resonances," Science, Vol. 317, no. 5834, pp. 83-86, Jul 2007.

[6] K. Sakai and Y. Sugasawa, "Ultralightweight motor design using electromagnetic resonance coupling," 2016 IEEE Energy Conversion Congress and Exposition (ECCE), Milwaukee, WI, 2016, pp. 1-7.

[7] Y. Sugasawa, K. Sakai, "Basic study on electromagnetic resonance motor", Proc. 2015 IEEJ Industry Application Society.

[8] K Sakai, K Takishima, "Frequency and operational characteristics of an ultra-lightweight machine converting energy by magnetic resonance coupling," 9th Int. Conf. on Pow. Electron. Mach. \& Driv. PEMD2018, Liverpool (UK), 17-19 Apr. 2018.

[9] A. Hughes and T. J. E. Miller, "Analysis of fields and inductances in air-cored and iron-cored synchronous machines," in Electrical Engineers, Proceedings of the Institution of, vol. 124, no. 2, pp. 121126, Feb. 1977. 